\title{
Readiness to Educate Patient: Indonesian Health Professionals' Perspective
}

\author{
Susi Ari Kristina ${ }^{1}$, Dian Anggraini Sayekti ${ }^{2} \&$ Yulianto $^{3}$ \\ ${ }^{1}$ Department of Pharmaceutics, Faculty of Pharmacy, Universitas Gadjah Mada, Yogyakarta, Indonesia \\ ${ }^{2}$ Research Assistant, Faculty of Pharmacy, Universitas Gadjah Mada, Yogyakarta, Indonesia \\ ${ }^{3}$ Vice Secretary of Regional Management, Indonesian Pharmacists Association, Yogyakarta, Indonesia \\ Correspondence: Susi Ari Kristina, Faculty of Pharmacy, Universitas Gadjah Mada, Sekip Utara Yogyakarta, \\ Indonesia 55281. Tel: 62-274-543-120. E-mail: susiari_k@ugm.ac.id
}

Received: May 10, 2018 Accepted: July 13, 2018 Online Published: July 25, 2018

doi:10.5539/gjhs.v10n8p117 URL: https://doi.org/10.5539/gjhs.v10n8p117

\begin{abstract}
The aim of this study was to investigate Indonesian health professionals' practice in educating patients and explore the perceived barriers. A self-administered questionnaire was given to the health professionals attending the Agent of Change (AoC) meeting in Yogyakarta Province, Indonesia. Data were explained by descriptive analysis. One hundred and twenty health professionals participated in this study. Majority participants were female (75.8\%), the mean of age were 46.74 (SD 5.32), pharmacists (63.3\%), work in primary health care (62.5\%), working experience $<5$ years $(54.2 \%)$, and had counseling experience (66.7\%). Name of medicine and its active ingredients was the most medication information which counselled by participants (3.67 \pm 1.22$)$. Limited time to communicate to the patients was the most barrier that perceived by health professionals $(70.8 \%)$. Improve the work efficiency is the key strategies. Health professionals can be effectively trained in counseling skills and be encouraged by constant monitoring of the obtained skills.
\end{abstract}

Keywords: health professionals, practice, provider, patient education, barrier

\section{Introduction}

In 2014, the Indonesian Government established a Universal Health Coverage as known as Jaminan Kesehatan Nasional (JKN) to provide a range of affordable healthcare to all Indonesians. The Ministry of Health through its health offices organised the health system into primary health care and public hospital. Within this new health system, health professionals can be involved either as a regulator or as practitioners (Mahendradhata et al., 2017). The implementation of Universal Health Coverage caused the increasing of health burden and the shortage of health professionals in Indonesia that has created opportunities to work in collaboration (Gilbert, Yan, \& Hoffman, 2010; Setiadi et al., 2017). Greater collaboration is effective in improving healthcare outcomes and enhancing drug management (Mulvale, Embrett, \& Razavi, 2016; Tan, Stewart, Elliott, \& George, 2014)

Health professionals play a central and critical role in improving patient care in many countries. In order to provide high-quality care, effective communication between health professional and patient is considered to be an essential requirement (Slort et al., 2011; World Health Organization, 2018). Patient education is an integral part of communication between health professional and patient. Past studies have shown that health-related advice from health professionals are considered very valuable by patients. Patient education in hospitals increase satisfaction and reduced anxiety and length of stay (Wensing et al., 2002)

Positive effects of patient education are decreasing the intensity and recurrence disease, reducing the return to the physician, and improving quality of life. But nevertheless the importance of patient education in health professionals' perspective, it's performing constantly has been ignored by many reasons that caused a mistake in patient's self-care and decrease the effectiveness of the medication (Dehaghani, Akhormeh, \& Mehrabi, 2012; Farahani, Sahragard, Carroll, \& Mohammadi, 2011; Gance-Cleveland, 2007). Other study indicated that patients who are not received essential educations, have more refers to doctors by $70 \%$ and rate of medical costs is higher. Consider not proper running of patient education in provider and its irreversible damage to patients and society, determining the barrier of patient education can beneficial for developing a key strategy and resolving these obstacles (Abdi, Izadi, Vafaeei, \& Lorestani, 2014). 
Thus, regarding the subject importance and lack of enough literature, this study was conducted to investigate Indonesian health professionals' practice in provider and explore the barriers to patient education perceived by health professionals.

\section{Methods}

\subsection{Study Design and Population}

This study was a cross-sectional survey study. The participants for the study were health professionals who have the working site in Yogyakarta, Indonesia and attended the coordination meeting held by Ministry of Health Republic of Indonesia, on 10-11 September 2017. Participants provided written informed consent before participating in the study.

\subsection{Questionnaire}

The validated questionnaire was developed based on focus group discussion among health professionals aimed to assess their perspective toward patient education. The questionnaire was previously piloted to 20 non-respondent health workers to examine its' validity and internal consistency with Cronbach Alpha ( $>0.7)$. The four sections of questionnaire included: First section was characteristics of participants (sex, age, profession, working site, working experience, counseling experience, providing health information services, and number of patient being counselled per day). Second part was concerned with health professionals' practice in provider and the third focused on the medications information which counselled in patient education, while the last sections concerned with the present barriers to patient education perceived by health professionals. The questionnaire was developed using the combination of multiple choice and Likert scale questions ( $1=$ never, $2=$ sometimes, $3=$ often, $4=$ very often). The questionnaire was answered based on participant's experiences.

\subsection{Data Collection}

Data were collected among health professionals who attended the Agent of Change (AoC) meeting as Health Office's program of Yogyakarta Province, Indonesia in September 2017. Necessary explanations about the aim of the study and assurance related to the right of confidentiality and anonymity were given before filling out the questionnaire.

\subsection{Data Analysis}

In this study, descriptive analysis was used to report the data. Characteristics of participants, health professionals' practice, and the barrier of patient education reported on frequency and percentage. Medication information that counselled of patient education reported on mean score and standard deviation (SD).

\section{Results}

A total of 120 participants agreed to participate. Characteristics of participants were summarized in Table 1. Most of participants were female (75.8\%), the mean of age were 46.74 (SD 5.32), pharmacist (63.3\%), work in primary health care $(62.5 \%)$, working experience $<5$ years $(54.2 \%)$, have counseling experience $(66.7 \%)$, currently providing health information services $(62.5 \%)$, and counselled $<3$ patients per day $(72.5 \%)$.

Health professionals' practice provider showed in Table 2. Most of the participants were to be part of the drug management $(74.2 \%)$, followed by providing service to the patient $(62.5 \%)$, and preparing medication to the patient (55.8\%). Meanwhile, the implementation of patient education reveals that name of medicine and its active ingredients (Table 3) was the most medication information which counselled by participants (3.67 1.22 ).

Table 4 outlines the barriers to patient education that perceived by health professionals. The barriers include health professional-related factors and patient-related factors. The most barriers to patient education were limited time between health professionals and patient to communicate (70.8\%). This finding supported by result above that most of health professionals worked in drug management that they were being overworked during the shift and have limited time to communicate with the patient. 
Table 1. Characteristics of participants

\begin{tabular}{|c|c|c|}
\hline Characteristics $(\mathrm{n}=120)$ & $\mathbf{N}$ & $\%$ \\
\hline \multicolumn{3}{|l|}{ Sex } \\
\hline Female & 91 & 75.8 \\
\hline Male & 29 & 24.2 \\
\hline Age (mean, SD) & \multicolumn{2}{|c|}{$46.74(5.32)$} \\
\hline \multicolumn{3}{|l|}{ Profession } \\
\hline Pharmacist & 76 & 63.3 \\
\hline Doctor & 18 & 15 \\
\hline Nurse & 14 & 11.7 \\
\hline Health promotor & 12 & 10 \\
\hline \multicolumn{3}{|l|}{ Working site } \\
\hline Primary health care & 75 & 62.5 \\
\hline Hospital & 32 & 26.7 \\
\hline Private clinic & 13 & 10.8 \\
\hline \multicolumn{3}{|l|}{ Working experience } \\
\hline$<5$ years & 65 & 54.2 \\
\hline $5-10$ years & 42 & 35 \\
\hline$>10$ years & 13 & 10.8 \\
\hline \multicolumn{3}{|l|}{ Counseling experience } \\
\hline Yes & 80 & 66.7 \\
\hline No & 40 & 33.3 \\
\hline \multicolumn{3}{|c|}{ Currently providing health information services } \\
\hline Yes & 75 & 62.5 \\
\hline No & 45 & 37.5 \\
\hline \multicolumn{3}{|c|}{ Number of the patient being counselled per day } \\
\hline$<3$ patients & 87 & 72.5 \\
\hline 3-5 patients & 30 & 25 \\
\hline$>5$ patients & 3 & 2.5 \\
\hline
\end{tabular}

Table 2. Health professionals' practice in provider

\begin{tabular}{lll}
\hline Practice (n=120) & $\mathbf{N}$ & $\mathbf{\%}$ \\
\hline Provide service to the patient & 75 & 62.5 \\
Preparing the medication to the patient & 67 & 55.8 \\
Administered the medicine to the patient & 56 & 46.7 \\
Interprofessional communication & 13 & 10.8 \\
Provide patient education & 20 & 16.7 \\
Manage the patient administration & 30 & 25 \\
To be part of the drug management & 89 & 74.2 \\
\hline
\end{tabular}


Table 3. Medication information counselled in patient education

\begin{tabular}{ll}
\hline Medication information & Mean score (SD) \\
\hline Name of the medicine and active ingredients & $3.67(1.22)$ \\
Indication & $3.21(1.41)$ \\
Dosage and frequency of intake & $2.78(1.76)$ \\
Medication administration & $2.50(1.98)$ \\
Side effects & $1.02(0.99)$ \\
\hline
\end{tabular}

Table 4. Barriers to patient education

\begin{tabular}{lcc}
\hline \multicolumn{1}{c}{ Type of barrier $(\mathbf{n = 1 2 0})$} & $\mathbf{N}$ & $\mathbf{\%}$ \\
\hline Health professional-related factors & 30 & 25 \\
Lack of knowledge regarding medication & 78 & 65 \\
Lack of training & 67 \\
Reluctance and low of self- confidence & 80 & 66.7 \\
Being overworked during the shift & 85 & 70.8 \\
Limited time to communicate & 56 \\
Lack of private area & 66.7 \\
No reimbursement / fund & 62 \\
Lack of organizational support & 10 \\
\hline Patient-related factors & 51.7 \\
Lack of interest & 12 \\
The clinical condition of the patient & 10.3 \\
Patient's mismatch & 20 \\
Patient inability to do the communication & 16.7 \\
\hline
\end{tabular}

\section{Discussion}

Health professionals' practice was complexed workload on the management of therapy and management of medicines in order to improve the quality of life to the patients (ABA, 2007). There has been limited research to investigate health professionals' practice in Indonesia and barrier that perceived in patient education. More than half of the participants admitted that they were pharmacists ward in primary health care that caused the most practice in provider was the management of drug. Pharmacists are trained to manage medicines throughout the drug procurement, supply, storage, and distribution process to minimize waste dan ensure quality care for patients. Pharmacists can assist the ward nurse with the ordering of medicines (Kehrer, Eberhart, Wing, \& Horon, 2013; Mayimele, Meyer, \& Schellack, 2015). Health professionals work as multidisciplinary teams to provide patient care, preparation the medication, and administered the rational medicines to the patients. All the process need interprofessional communication. Health professionals assuming complementary roles and cooperatively working together, sharing responsibility for problem-solving and making decisions to formulate and carry out plans for patient care (Hall, 2005). Unfortunately, many health professionals were used to poor communication and teamwork because there were some barriers to interprofessional collaboration such as historical interprofessional and intra-professional rivalries, the difference in language and jargon, and differences in schedules and professional routines (O'Daniel \& Rosenstein, 2008). The past study showed that patient education was effective to patient outcome but sometimes lack motivation among health professionals (Lelorain, Bachelet, Bertin, \& Bourgoin, 2017)

Discussion among health professionals (pharmacist and physician group) were conducted to determine the importance of medication information which counselled to the patient. The study stated that health professional should be told the medicine name, purpose, direction (including number of pills, frequency, and timing of intake), potential side effect, and how long to take the medication. Physician hesitates to counsel the side effect due to fear 
of alarming patient and creating nonadherence. On the counselling, physician mention giving information about medication refills and desired therapeutic goals and the pharmacists stated that name of medicine and its active ingredients was the most important information that should be counselled to the patients (Raynor, 2007; Tarn, Paterniti, Williams, Cipri, \& Wenger, 2009).

In this study finding that being high workload among health professionals was the most common barrier to patient education that caused they had limited time to educate patients and lack of training. They were being overworked because increased of the patients and also high workload on drug management. Abdi et al (2014) reported that the importance of patient education was high but it was performed in low level. High workload and mismatch of personnel to the patient were posed as the most barriers. Mismatch of personnel to the patient cause failure in patient education. Hermansyah et al. (2018) report that JKN system has made primary health care as a first choice for care among patients and has resulted in a significant increase in patient visits. This, in turn, has increased the workload of health professionals. This study also highlighted the commonalities of pharmacists' practice in primary health care are predominantly focused on preparation and dispensing pharmaceuticals. The increase in patient visit made the pharmacists have limited time to communicate to the patient. From the general practitioners' perspective, lack of enough time, increase the number of patients, lack of patients physical readiness and interest for learning, medication knowledge deficiency of health professionals about patient education, and reluctant of patient to learning have original role in lack of implementation of patient education (Cianciara \& Miller, 2003). Abraham et al (2017) study that lack of private area lead the patient embarrassed, uncomfortable, shy, and easily distracted. The clinical condition of the patients that they were too ill and inability to communication among patients with chronic disease lead the barriers to patient education (Norouzinia, Aghabarari, Shiri, Karimi, \& Samami, 2016). Lack of enough confidence and poor organization support are main cause of lack of patient education. It is believed that there is high level of dissatisfaction in health professionals cause of inadequate fund, lack of appropriate opportunity for training, and few professionals staff (Yami, Hamza, Hassen, Jira, \& Sudhakar, 2011).

The differences barrier among health professionals can be due to lack of appropriate interaction and their different educational background. Studies show that increase in interaction and communication between pharmacists, doctor, nurse and allied health professionals results in better patient education. Lack of coordination and communication between allied health professionals is important accordingly obstacles to patient education (Abdi et al., 2014). We are aware of the limitations of the present study. First, it was a high number of pharmacists in this study and conducted in a single setting, therefore the sample may not be representative of all Indonesian health professionals. It is recommended that future studies may develop the research in the larger field. Participants who attend the meeting were only those who had high motivation to learn and it was prone to selection bias. Second, the data was use of the self-reporting system employed in this study. This may have given rise to information bias.

\section{Conclusions}

The finding of the study showed that health professionals' practice imbalanced between system management and therapy management. Indonesian health professionals spent their time on high workload that caused lack of implementation of patient education. Establishing the system that improves the work efficiency will be considerably helpful to reduce health professionals' workload in management. Training in counselling skill and knowledge about patient counseling will allocate the health professionals to prepare their readiness and self-confidence to provide patient education. Future research, explore interventions to realized the ideal patient education should be interest because their substance may improve readiness health professionals in educating patient and quality of life to the patients.

\section{Acknowledgments}

We thank all health professionals who participated in this study and health office who facilitate the meeting and helped in the collection of data.

\section{Competing Interests Statement}

The authors declare that there are no competing or potential conflicts of interest.

\section{References}

ABA, A. B. A. (2007). Guidance to nurses and midwives on medication management: An Bord Altranais (ABA).

Abdi, A., Izadi, A., Vafaeei, K., \& Lorestani, E. (2014). Assessment of Patient education barriers in viewpoint of nurses and general physicians. International Research Journal of Applied and Basic Sciences, 8(12), $2252-2256$. 
Abraham, O., Alexander, D. S., Schleiden, L. J., \& Carpenter, D. M. (2017). Identifying Barriers and Facilitators at Affect Community Pharmacists' Ability to Engage Children in Medication Counseling: A Pilot Study. The Journal of Pediatric Pharmacology and Therapeutics, 22(6), 412-422. https://doi.org/10.5863/1551-6776-22.6.412

Cianciara, D., \& Miller, M. (2003). Physicians's attitude toward patient education. Przeglad epidemiologiczny, 57(3), 531-540.

Dehaghani, A. R., Akhormeh, K. A., \& Mehrabi, T. (2012). Assessing the effectiveness of interpersonal communication skills training on job satisfaction among nurses in Al-Zahra Hospital of Isfahan, Iran. Iranian Journal of Nursing and Midwifery Research, 17(4), 290-8.

Farahani, M. A., Sahragard, R., Carroll, J. K., \& Mohammadi, E. (2011). Communication barriers to patient education in cardiac inpatient care: A qualitative study of multiple perspectives. International Journal of Nursing Practice, 17(3), 322-328. https://doi.org/10.1111/j.1440-172X.2011.01940.x

Gance-Cleveland, B. (2007). Motivational interviewing: improving patient education. Journal of Pediatric Health Care, 21(2), 81-88. https://doi.org/10.1016/j.pedhc.2006.05.002

Gilbert, J. H., Yan, J., \& Hoffman, S. J. (2010). A WHO report: framework for action on interprofessional education and collaborative practice. Journal of Allied Health, 39(3), 196-197.

Hall, P. (2005). Interprofessional teamwork: Professional cultures as barriers. Journal of Interprofessional care, 19(sup1), 188-196. https://doi.org/10.1080/13561820500081745

Hermansyah, A., Sainsbury, E., \& Krass, I. (2018). Investigating the impact of the universal healthcare coverage programme on community pharmacy practice. Health \& Social Care in the Community, 26(2), e249-e260. https://doi.org/10.1111/hsc.12506

Kehrer, J. P., Eberhart, G., Wing, M., \& Horon, K. (2013). Pharmacy's role in a modern health continuum. Canadian Pharmacists Journal/Revue des Pharmaciens du Canada, 146(6), 321-324. https://doi.org/10.1177/1715163513506370

Lelorain, S., Bachelet, A., Bertin, N., \& Bourgoin, M. (2017). French healthcare professionals' perceived barriers to and motivation for therapeutic patient education: A qualitative study. Nursing \& Health Sciences, 19(3), 331-339. https://doi.org/10.1111/nhs.12350

Mahendradhata, Y., Trisnantoro, L., Listyadewi, S., Soewondo, P., Marthias, T., Harimurti, P., \& Pawira, J. (2017). The Republic of Indonesia Health System Review (Vol. 7). India: World Health Organization.

Mayimele, N., Meyer, H., \& Schellack, N. (2015). What role does the pharmacist play in medicine management at ward level? SA Pharmaceutical Journal, 82(1), 33-36.

Mulvale, G., Embrett, M., \& Razavi, S. D. (2016). 'Gearing Up'to improve interprofessional collaboration in primary care: a systematic review and conceptual framework. BMC Family Practice, 17(1), 83. https://doi.org/10.1186/s12875-016-0492-1

Norouzinia, R., Aghabarari, M., Shiri, M., Karimi, M., \& Samami, E. (2016). Communication barriers perceived by nurses and patients. Global Journal of Health Science, 8(6), 65. https://doi.org/10.5539/gjhs.v8n6p65

O'Daniel, M., \& Rosenstein, A. H. (2008). Professional communication and team collaboration.

Raynor, D. (2007). The importance of medicines information for patients. Prescriber, 18(2), 60-62. https://doi.org/10.1002/psb.15

Setiadi, A. P., Wibowo, Y., Irawati, S., Setiawan, E., Presley, B., Gudka, S., \& Wardhani, A. S. (2017). Indonesian pharmacists' and pharmacy students' attitudes towards collaboration with physicians. Pharmacy Practice, 15(4),1-7. https://doi.org/10.18549/PharmPract.2017.04.1052

Slort, W., Schweitzer, B. P., Blankenstein, A. H., Abarshi, E. A., Riphagen, I., Echteld, M. A., . . Deliens, L. (2011). Perceived barriers and facilitators for general practitioner-patient communication in palliative care: a systematic review. Palliative Medicine, 25(6), 613-629. https://doi.org/10.1177/0269216310395987

Tan, E. C., Stewart, K., Elliott, R. A., \& George, J. (2014). Pharmacist services provided in general practice clinics: a systematic review and meta-analysis. Research in Social and Administrative Pharmacy, 10(4), 608-622. https://doi.org/10.1016/j.sapharm.2013.08.006

Tarn, D. M., Paterniti, D. A., Williams, B. R., Cipri, C. S., \& Wenger, N. S. (2009). Which providers should communicate which critical information about a new medication? Patient, pharmacist, and physician 
perspectives. Journal of the American Geriatrics Society, 57(3), $462-469$. https://doi.org/10.1111/j.1532-5415.2008.02133.x

Wensing, M., Vedsted, P., Kersnik, J., Peersman, W., Klingenberg, A., Hearnshaw, H., . . . Mendive, J. (2002). Patient satisfaction with availability of general practice: an international comparison. International Journal for Quality in Health Care, 14(2), 111-118. https://doi.org/10.1093/oxfordjournals.intqhc.a002597

World Health Organization. (2018). Health Professions Networks. Retrieved 30 April, 2018, from http:/www.who.int/hrh/professionals/en/

Yami, A., Hamza, L., Hassen, A., Jira, C., \& Sudhakar, M. (2011). Job satisfaction and its determinants among health workers in jimma university specialized hospital, southwest ethiopia. Ethiopian Journal of Health Sciences, 21(3).

\section{Copyrights}

Copyright for this article is retained by the author(s), with first publication rights granted to the journal.

This is an open-access article distributed under the terms and conditions of the Creative Commons Attribution license (http://creativecommons.org/licenses/by/4.0/). 